DOI: $10.15593 / 24111678 / 2016.03 .08$

УДК 625.712

\author{
Е.Д. Остерман, О.А. Шутова \\ Пермский национальный исследовательский \\ политехнический университет, Пермь, Россия \\ ИССЛЕДОВАНИЕ ПЕШЕХОДНОГО ПОТОКА \\ НА КОЛХОЗНОЙ ПЛОЩАДИ В ГОРОДЕ ПЕРМИ
}

\begin{abstract}
В мире ежегодно в результате ДТП гибнет огромное количество человек. Более одной пятой смертельных случаев приходится на долю пешеходов. В связи с тем, что уровень автомобилизации растет с каждым днем, вопрос безопасности пешеходов стоит наиболее остро. Единственным правильным решением в такой ситуации может стать устройство безопасных пешеходных переходов. В г. Перми одним из наиболее напряженных мест относительно пешеходного и транспортного движения является Колхозная площадь.

Объектом данного исследования является пешеходный поток на Колхозной площади в г. Перми. Цель работы заключается в том, чтобы установить параметры пешеходного потока на данной территории, факторы, влияющие на него, а также выявить наиболее загруженные дни недели и время суток.

Был проанализирован пешеходный поток на четырех наземных пешеходных переходах. Данные об интенсивности пешеходного движения собирались и замерялись натурным образом. Приведены сведения о количестве дорожно-транспортных происшествий в Пермском крае. Выделены четыре группы факторов (градостроительные, дорожно-планировочные, социальные, экономические), влияющих на пешеходный поток. Выявлена основная проблема сложившейся сложной ситуации в области пешеходного и транспортного движения на Колхозной площади. Рассмотрены все существующие в районе площади пешеходные переходы. Исследовано отношение жителей города к состоянию транспортного узла в данном районе.

Установлено, что на пешеходных переходах в районе Колхозной площади наблюдается значительный поток пешеходов. На трех из четырех наибольший поток пешеходов наблюдается в среду, наименьший - в субботу, наименьшее количество пешеходов отмечено в утреннее время. На одном из пешеходных переходов рекомендуется создать внеуличный пешеходный переход.

Ключевые слова: пешеходный поток, пешеходы, интенсивность пешеходного движения, пешеходный переход, типы пешеходных переходов, Колхозная площадь г. Перми, центры тяготения.
\end{abstract}

\author{
E.D. Osterman, O.A. Shutova
}

Perm National Research Polytechnic University, Perm, Russian Federation

\title{
RESEARCH ON PEDESTRIAN TRAFFIC FLOW OF KOLKHOZNAIA SQUARE IN PERM
}

Every year in the world a huge number of people are killed in road accidents. More than onefifth of these deaths are among pedestrians. Due to the fact that in the modern world, automobilization level is increasing with each passing day, question of the safety of pedestrians will arise definitely. The only right thing to do in such situation will be creating of safe pedestrian crossings. In Perm one of the most stressful places in the area of pedestrian and car traffic is Kolkhoznaia square. 
The object of this research is pedestrian traffic flow of Kolkhoznaia square in Perm. The purpose of work is to set the parameters of pedestrian traffic flow in this territory, the factors that affecting it and to identify the busiest days of the week and time of day.

In this article pedestrian traffic flow analysis on four ground pedestrian crossings was made. The data on the intensity of pedestrian traffic flow was collected and measured on location. The data on the number of road accidents in Perm Territory is presented. Four groups of factors (urban planning, traffic-planning, social, economic) that affect pedestrian flow are examined. The main problem of the current difficult situation in the field of pedestrian and vehicle traffic of Kolkhoznaia square is revealed. All existing pedestrian crossings in the area of the square are examined. Attitude of city residents to the transport hub state near Kolkhoznaia square is revealed.

As a result of the work is determined that there is a significant flow on the pedestrian crossings in the area of Kolkhoznaia square. In three of the four pedestrian crossings the greatest flow of pedestrians is observed on Wednesday, the lowest on Saturday, the smallest number of pedestrians is observed in the morning. Also it found that in one of the pedestrian crossings must be the off-street pedestrian crossing.

Keywords: pedestrian traffic flow, pedestrians, intensity of pedestrian traffic, pedestrian crossing, types of pedestrian crossings, Kolkhoznaia square, Perm, centers of gravity.

С появлением автомобильного транспорта в течение продолжительного времени внимание градостроителей было сосредоточено на формировании автотранспортной системы, а пешеходная система организовывалась по остаточному принципу и формально [1].

Сегодня в мире уровень автомобилизации растет с каждым днем. Эксперты аналитического агентства «Автостат» выяснили, что по состоянию на 1 июля 2015 г. в России в среднем на каждую тысячу человек приходится 284 автомобиля [2]. Однако данные показатели значительно отстают от показателей европейских стран и США. В Соединенных Штатах уровень автомобилизации составляет 799 авт./тыс. жителей, в Италии - 618 авт./тыс. жителей, в Германии - 544 авт./тыс. жителей, в Чехии - 458 авт./тыс. жителей.

Несмотря на относительно невысокий уровень автомобилизации, Россия имеет очень высокий показатель смертности в ДТП, при этом более одной пятой этих случаев приходится на долю пешеходов.

В Пермском крае, по сведениям управления ГИБДД ГУ МВД России, за период с января по ноябрь 2015 г. было зарегистрировано 3795 случаев ДТП, 1228 из них связаны с наездом на пешеходов. Данный показатель ниже на 6,5 \% по сравнению с аналогичным периодом предыдущего года [3].

В г. Перми одним из наиболее напряженных мест относительно пешеходного и транспортного движения является Колхозная площадь, которая находится между Центральным рынком и автовокзалом, соединяя шоссе Космонавтов с улицами Попова, Пушкина и Революции. В районе Колхозной площади можно выделить три главных го- 
родских центра тяготения: Пермская краевая клиническая больница, автовокзал, Центральный рынок. Краевую клиническую больницу можно отнести к лечебно-физкультурной группе учреждений, автовокзал - к административно-общественной, Центральный рынок - к торгово-бытовой. Кроме того, рядом расположены такие центры тяготения, как ТЦ «Семь пятниц», клуб «7», клиника «Философия красоты и здоровья», Пермское отделение пенсионного фонда РФ, ЗападноУральский банк ОАО «Сбербанк России», общежитие Пермской государственной медицинской академии, сеть салонов-магазинов «МТС», «Билайн», «Евросеть» и др. При этом нужно иметь в виду, что все группы учреждений имеют разную периодичность посещения.

На рис. 1 представлены три основных центра тяготения в районе Колхозной площади.

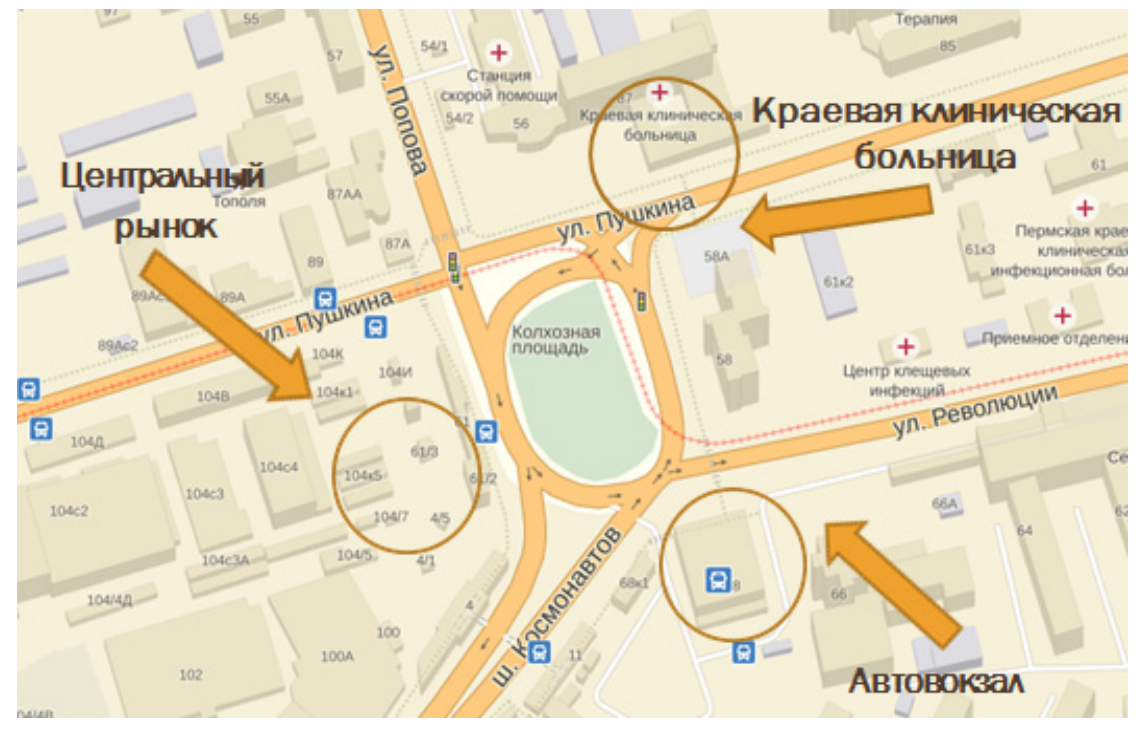

Рис. 1. Основные центры тяготения в районе Колхозной площади

Таким образом, можно сделать вывод о наличии в районе площади большого числа центров тяготения для транспорта и пешеходов. Следует также отметить трудности, связанные с использованием данной территории.

Для пешеходного движения проблему составляют состояние пешеходных путей, их суженность, наличие большого количества препятствий на пути движения, необходимость пересекать транспортные пути и т.п. 
Анализ интернет-источников показал, что многие жители города недовольны состоянием пешеходных путей в районе Колхозной площади. В качестве основных проблем горожанами были названы большая протяженность путей через площадь и небезопасность подземных пешеходных переходов в этом районе.

Проблемами Колхозной площади г. Перми в области транспортного движения являются низкая пропускная способность улиц и пересечений; совмещенное движение общественного пассажирского транспорта, легкового и грузового движения; практически отсутствие системы обеспечения парковок в городе. Из-за хаотично припаркованного частного автотранспорта подход к остановочным комплексам значительно затруднен $[4,5]$.

Таким образом, транспортный узел в районе Колхозной площади сильно перегружен, и разгрузить его не удастся, поскольку три главных центра тяготения города невозможно перенести в другое место, а также нельзя избавиться от стесненности территории. Уличнодорожная сеть (УДС) г. Перми создавалась десятилетиями, и для ее изменения необходимы время и значительные инвестиции. На наш взгляд, в таких условиях в качестве первоочередных необходимы административные меры по ограничению использования личных автомобилей на Колхозной площади, чтобы уменьшить количество автомобилей до уровня, не превышающего пропускную способность УДС и емкость парковок в городе [6].

В настоящее время на данном участке присутствуют нерегулируемый, регулируемый и подземный пешеходные переходы. Их расположение представлено на рис. 2.

Пешеходный переход - это участок проезжей части, трамвайных путей, обозначенный знаками и (или) разметкой и выделенный для движения пешеходов через дорогу. Пешеходным переходом может быть также искусственное сооружение над или под проезжей частью, которое предназначено для тех же целей.

Нерегулируемый пешеходный переход на Колхозной площади предназначен для пересечения ул. Революции. Нерегулируемые переходы самые простые и недорогие, но при этом люди подвергаются наибольшей опасности. Сейчас довольно много людей предпочитает сделать крюк, но не рисковать жизнью на нерегулируемых переходах $[7,8]$. 
Регулируемый пешеходный переход на Колхозной площади предназначен для пересечения ул. Пушкина в двух местах, а также ул. Попова. Данный вид пешеходных переходов имеет светофоры, следовательно, по сравнению с нерегулируемым, приводит к снижению количества наездов на пешеходов, пострадавших и погибших. Плюсом также является то, что обустройство регулируемого пешеходного перехода дешевле, чем устройство внеуличных пешеходных переходов (надземных и подземных). К его минусам можно отнести то, что, даже если установлен светофор, автомобилисты и пешеходы часто не соблюдают правила дорожного движения [9].

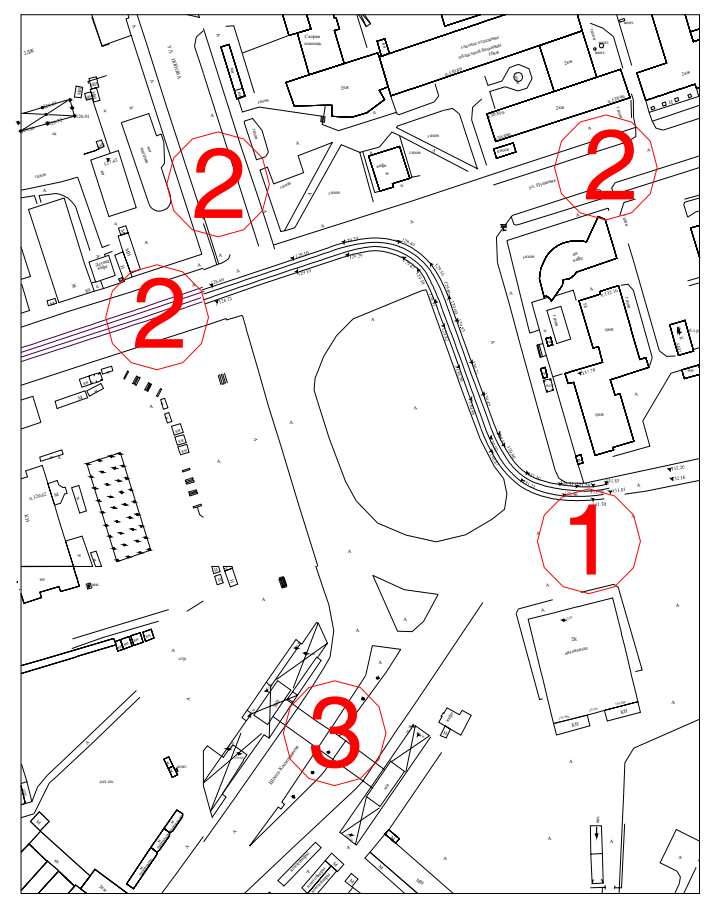

Рис. 2. Типы пешеходных переходов на Колхозной площади:

1 - нерегулируемый; 2 - регулируемый; 3 - подземный

Подземный пешеходный переход на Колхозной площади предназначен для пересечения шоссе Космонавтов. Подземные пешеходные переходы, в отличие от всех остальных, практически не нарушают архитектурный облик города. Они являются наиболее удобными и безопасными для пешеходов. К их минусам можно отнести сложность проектирования, высокий уровень ответственности, строительство таких 
переходов требует достаточно больших средств и переноса подземных коммуникаций, в процессе строительства необходимо перекрытие улицы для выполнения работ $[10,11]$.

На основании сказанного можно сделать вывод о том, что на Колхозной площади следует изменить организацию пешеходного движения для обеспечения доступности точек тяготения.

Можно выделить четыре группы факторов, влияющих на пешеходный поток:

- градостроительные;

- дорожно-планировочные;

- социальные;

- экономические [12].

К первой группе факторов относят места расположения в плане города пунктов тяготения пешеходов. Исходя из расположения центров тяготения, можно определить основные направления и объемы пешеходного движения. Пешеходное движение достаточно тесно связано с функциональным назначением объектов.

В торговых узлах пешеходный поток непрерывен в течение рабочего дня. Количество посетителей определяется крупностью торгового предприятия, при этом зависит от режима работы данного учреждения. Поток людей включает в себя представителей разных возрастных групп, у большинства из них имеется ручная кладь.

В транспортных узлах пешеходный поток соответствует режиму работы пассажирского транспорта. По составу он неоднороден, у большинства людей отмечается наличие ручного груза. Интенсивность движения связана с прибытием и отправлением городского транспорта.

Около учреждений здравоохранения пешеходный поток непрерывный, но соответствует режиму работы учреждения. Он включает людей разных возрастных групп, а также маломобильные группы населения.

Дорожно-планировочные факторы рассматривают основные показатели, которые характеризуют пешеходный поток, а именно: интенсивность, плотность и скорость.

Интенсивность пешеходного потока $N_{\text {пеш }}$ - численность пешеходов, проходящих через определенное сечение пути в единицу времени. Данный показатель может колебаться в достаточно широких пределах. Интенсивность пешеходного потока зависит от функционального назначения улицы или дороги и от расположенных на них объектов притяже- 
ния. Наиболее высокая интенсивность движения пешеходов обычно наблюдается на главных и торговых улицах крупных городов, а также в зоне транспортных пересадочных узлов (вокзалов, станций метрополитена). Пешеходные потоки характеризуются значительной временной неравномерностью в течение суток, которая также зависит от назначения улицы и расположенных на ней объектов притяжения [13].

Плотность пешеходного потока $q_{\text {пеш }}$ - численность пешеходов, приходящихся на $1 \mathrm{~m}^{2}$ площади. Плотность пешеходного потока $q_{\text {пеш }}$ колеблется в широких пределах. Она оказывает влияние на скорость движения пешеходов и пропускную способность пешеходных путей. Предельная плотность пешеходного потока определяется с помощью габаритных размеров движущихся объектов. Так, например, человек в статическом положении в летней одежде занимает меньшую площадь, чем в зимней одежде, а при наличии ручной клади площадь увеличивается еще больше. Таким образом, в зависимости от плотности можно выделить свободное и стесненное движение. При свободных условиях $\left(q_{\text {пеш }} \leq 0,5\right.$ чел./м $\left.{ }^{2}\right)$ человек в любое время может изменить скорость и направление своего движения. В стесненных условиях $\left(q_{\text {пеш }}>0,5\right.$ чел./ $\left.\mathrm{M}^{2}\right)$ ограничиваются свобода и возможность изменять режим движения людей. При дистанции 2 м между движущимися в колонне людьми движение пешеходного потока можно назвать свободным. Значительные помехи будут наблюдаться при плотности движе-

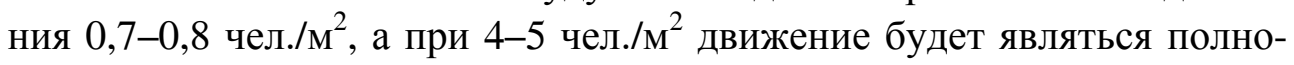
стью стесненным, но поток еще сможет медленно двигаться.

Скорость пешеходного потока $v_{\text {пеш }}$ - это скорость передвижения пешеходов в потоке. Скорость движения человека зависит от множества факторов: возраста и состояния здоровья, цели передвижения, дорожных условий, состояния окружающей среды. Средняя скорость движения человека спокойным шагом составляет $0,5-1,5$ м/с. Интересным фактом является то, что на переходах большей длины скорость пешеходов становится выше, поскольку возрастает чувство опасности столкновения с транспортным средством. Так, при движении по наземным пешеходным переходам при малой плотности движения скорость составляет 1,1-1,5 м/с, а при высокой - 0,6-0,9 м/с [14].

К социальным факторам можно отнести состав пешеходного потока по возрасту и дисциплине пешеходов. Когда пешеход торопится или опаздывает, он идет по кратчайшему расстоянию, при этом не исключено, что он нарушит правила дорожного движения. Всем людям присуще 
естественное стремление экономить время и усилия на передвижение. Таким образом, дисциплина пешеходов в большей степени зависит от того, насколько совпадают коммуникационные пути и кратчайшие расстояния.

Экономические факторы включают в себя затраты на строительство, содержание пешеходных путей, а также удобство и безопасность пешеходного движения.

Для принятия правильных решений по организации пешеходного движения необходимо в первую очередь обеспечить точность исходных показателей, одним из которых является интенсивность движения пешеходов.

Исследования проводились на четырех наземных пешеходных переходах на Колхозной площади г. Перми в период со 2 марта до 21 марта 2016 г. Данные об интенсивности пешеходного движения собирались и замерялись натурным образом в следующие промежутки времени: с 7:00 до 8:00, с 12:00 до 13:00 и с 17:00 до 18:00 [15]. Наблюдения проводились в рабочие дни недели (понедельник, среда, пятница) и в субботу. В рабочие дни проводилось по два замера, в субботу - один. Кроме того, для выявления объема пешеходного потока в каждом направлении движения был произведен замер в понедельник с 12:00 до 13:00.

На рис. 3 представлены номера исследуемых пешеходных переходов.

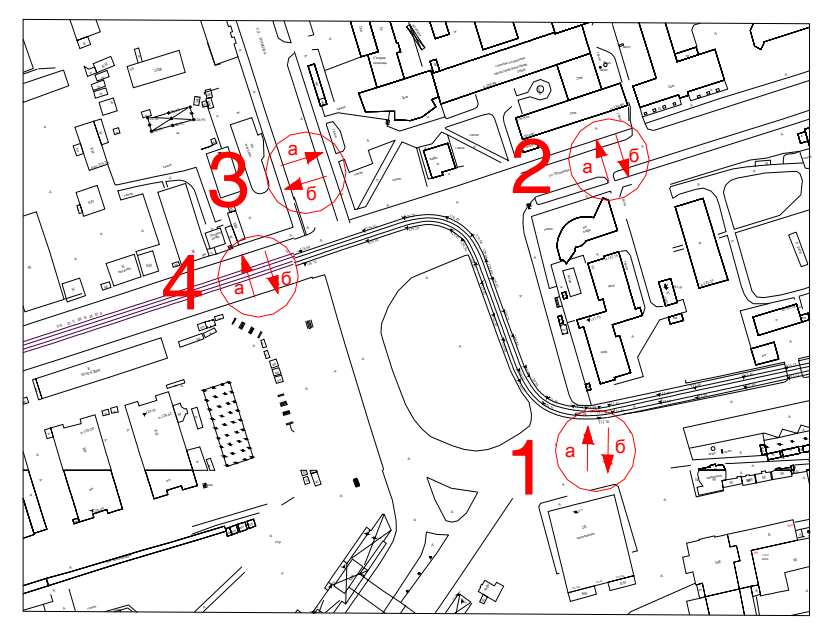

Рис. 3. Исследуемые пешеходные переходы 
Первый пешеходный переход - нерегулируемый, предназначен для пересечения ул. Революции через трамвайные пути. На рис. 4 представлена диаграмма распределения пешеходного потока по дням недели и времени суток на пешеходном переходе № 1.

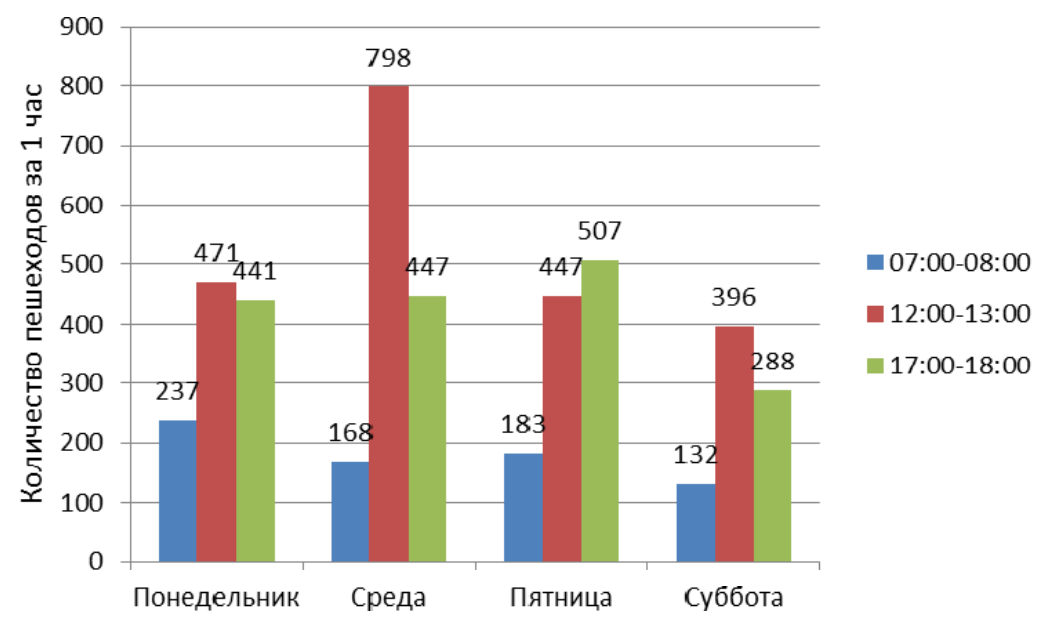

Рис. 4. Диаграмма распределения пешеходного потока по дням недели и времени суток на пешеходном переходе № 1

Наименьшее количество пешеходов наблюдается на пешеходном переходе № 1 в промежуток времени с 7:00 до 08:00, наибольшее в обеденное время (с 12:00 до 13:00), за исключением пятницы, когда наибольшее количество пешеходов было отмечено в вечернее время. Это связано с наличием такого центра тяготения, как автовокзал, и отъездом людей из города на выходные. Наибольший пешеходный поток наблюдался в среду, наименьший - в субботу.

Второй пешеходный переход - регулируемый, предназначен для пересечения ул. Пушкина. На рис. 5 представлена диаграмма распределения пешеходного потока по дням недели и времени суток на пешеходном переходе № 2.

Наименьшее количество пешеходов наблюдается на пешеходном переходе № 2 в промежуток времени с 7:00 до 08:00, наибольшее в вечернее время (с 17:00 до 18:00), за исключением среды. Наибольший пешеходный поток наблюдался в пятницу, наименьший в субботу. 


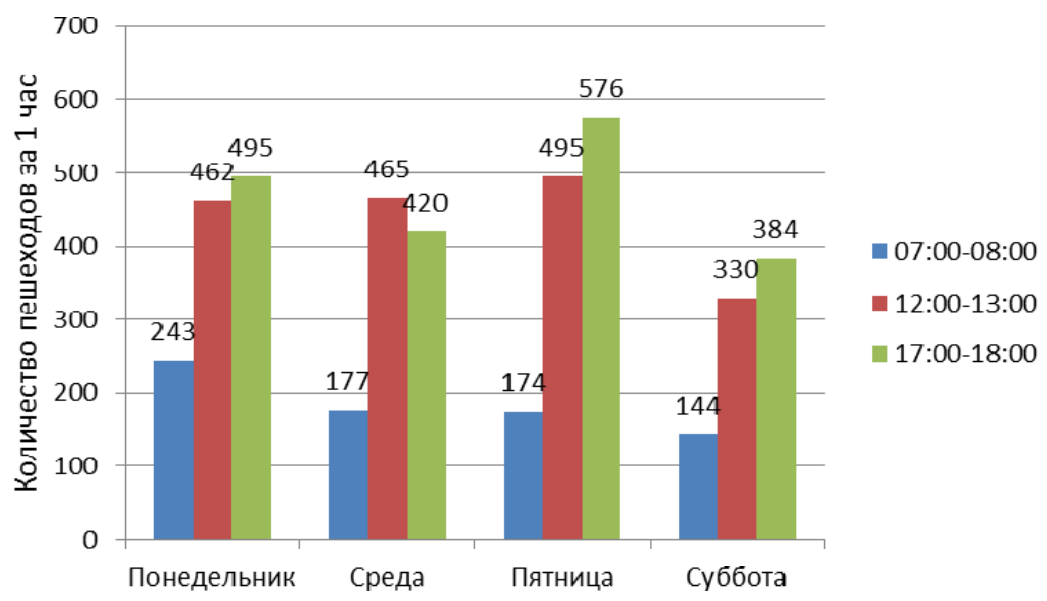

Рис. 5. Диаграмма распределения пешеходного потока по дням недели и времени суток на пешеходном переходе № 2

Третий пешеходный переход - регулируемый, предназначен для пересечения ул. Попова. На рис. 6 представлена диаграмма распределения пешеходного потока по дням недели и времени суток на пешеходном переходе № 3 .

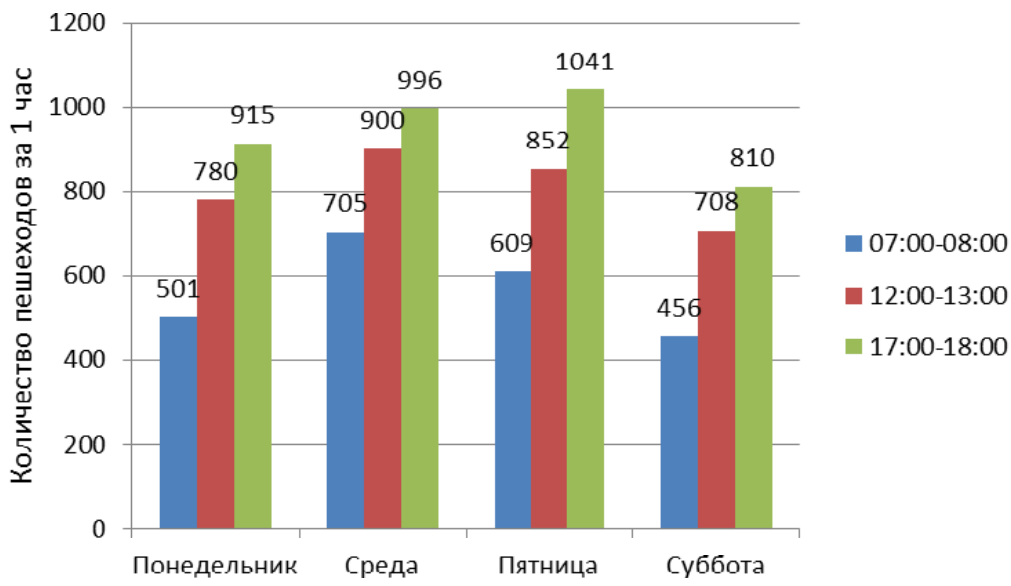

Рис. 6. Диаграмма распределения пешеходного потока по дням недели и времени суток на пешеходном переходе № 3

Наименьшее количество пешеходов наблюдается на пешеходном переходе № 3 в промежуток времени с 7:00 до 08:00, наибольшее в вечернее время (с 17:00 до 18:00). Наибольший пешеходный поток был отмечен в среду, наименьший - в субботу. 
Четвертый пешеходный переход - регулируемый, предназначен для пересечения ул. Пушкина через трамвайные пути. На рис. 7 представлена диаграмма распределения пешеходного потока по дням недели и времени суток на пешеходном переходе № 4.

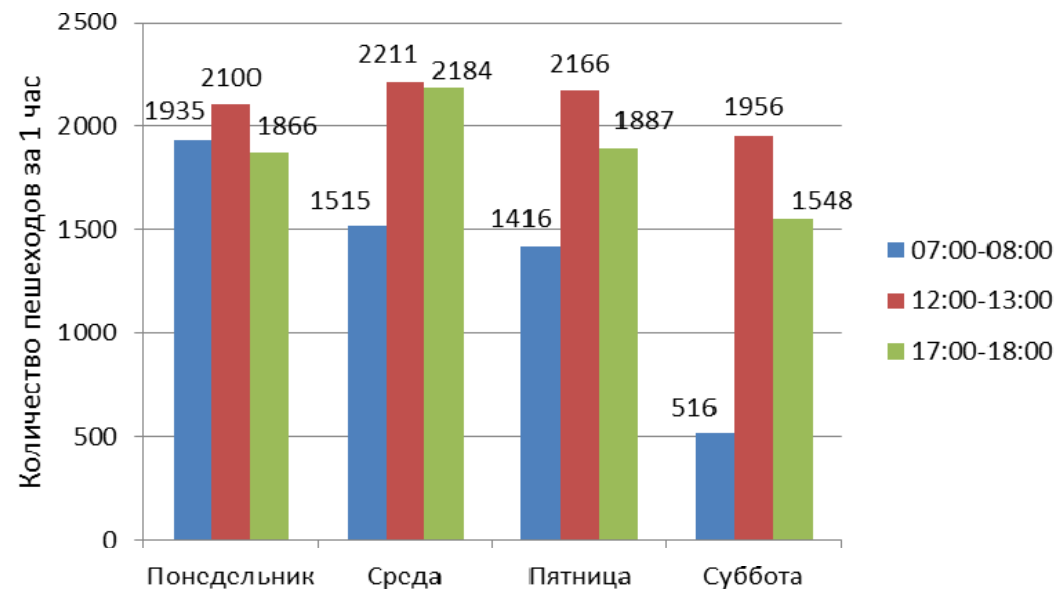

Рис. 7. Диаграмма распределения пешеходного потока по дням недели и времени суток на пешеходном переходе № 4

Наименьшее количество пешеходов наблюдается на пешеходном переходе № 4 в промежуток времени с 7:00 до 08:00, наибольшее в обеденное время (с 12:00 до 13:00). Наибольший пешеходный поток был отмечен в среду, наименьший - в субботу.

На первом пешеходном переходе среднее количество пешеходов за 1 ч составляет 377 человек, на третьем - 773. Наибольшее количество пешеходов было зафиксировано на пешеходном переходе № 4 (1775 чел.), наименьшее - на пешеходном переходе № 2 (364 чел.). Такую ситуацию можно объяснить тем, что пешеходный переход № 4 ближе всех расположен к двум наиболее значимым центрам тяготения (Центральный рынок и автовокзал) данной территории. К тому же в непосредственной близости от перекрестка находятся остановки общественного транспорта.

Анализ нормативных документов показал, что в настоящее время вопросы организации пешеходных переходов рассмотрены детально только в одном документе - МГСН 1.03-02 «Пешеходные переходы вне проезжей части улиц», - разработанном для Москвы. Для Перми аналогичного документа нет, поэтому для разработки предложений по 
организации пешеходного движения на площади было принято решение рассмотреть нормы, приведенные в МГСН.

Согласно МГСН 1.03-02 на улицах с регулируемым движением при ширине проезжей части улицы более 14 м и величине потока пешеходов, превышающей 1500 чел./ч, необходимо предусматривать пешеходные переходы вне проезжей части. Пешеходный переход № 4 удовлетворяет данным требованиям, следовательно, на нем необходимо создать внеуличный пешеходный переход.

В таблице показано распределение пешеходного потока на четыpex переходах в двух направлениях в понедельник 21 марта 2016 г. в промежуток с 12:00 до 13:00.

Распределение пешеходного потока на четырех переходах в двух направлениях

\begin{tabular}{|c|c|c|c|}
\hline \multirow{2}{*}{$\begin{array}{c}\text { Номер } \\
\text { пешеходного } \\
\text { перехода }\end{array}$} & \multicolumn{2}{|c|}{$\begin{array}{c}\text { Количество человек за } 10 \text { мин на различных } \\
\text { направлениях движения пешеходного потока }\end{array}$} & $\begin{array}{c}\text { Общее } \\
\text { количество } \\
\text { человек } \\
\text { за 10 мин }\end{array}$ \\
\hline 1 & Направление $a$ & Направление $\sigma$ & 80 \\
\hline 2 & 42 & 38 & 79 \\
\hline 3 & 39 & 40 & 133 \\
\hline 4 & 56 & 77 & 350 \\
\hline
\end{tabular}

Исходя из таблицы, приведенной выше, видно, что на перекрестках № 1 и 2 наблюдается незначительная разница в значениях в двух направлениях. На перекрестках № 3 и 4 отмечается большее количество человек в направлении $\sigma$, которое ведет к таким центрам тяготения, как Центральный рынок и автовокзал. Данное явление можно объяснить режимом работы (открытие в 10:00) Центрального рынка.

Таким образом, в результате проделанной работы можно сделать следующие выводы:

1. На пешеходных переходах в районе Колхозной площади наблюдается значительный поток пешеходов. В первую очередь это связано с тем, что на данной территории сосредоточены целых три крупных центра тяготения.

2. Количество пешеходов за 1 ч возрастает на пешеходных переходах в следующем порядке: регулируемый пешеходный переход, предназначенный для пересечения ул. Пушкина (№ 2); нерегулируе- 
мый пешеходный переход, предназначенный для пересечения ул. Революции через трамвайные пути (№ 1); регулируемый пешеходный переход, предназначенный для пересечения ул. Попова (№ 3); регулируемый пешеходный переход, предназначенный для пересечения ул. Пушкина через трамвайные пути (№ 4).

3. На трех из четырех пешеходных переходов наибольший поток пешеходов наблюдается в среду, наименьший - в субботу.

4. Наименьшее количество пешеходов было отмечено в утреннее время (07:00-08:00), наибольшее - на нерегулируемом пешеходном переходе, предназначенном для пересечения ул. Революции через трамвайные пути (№ 1), и на регулируемом пешеходном переходе, предназначенном для пересечения ул. Пушкина через трамвайные пути (№ 4) (в промежуток с 12:00 до 13:00), а также на регулируемом пешеходном переходе, предназначенном для пересечения ул. Пушкина (№ 2), и на регулируемом пешеходном переходе, предназначенном для пересечения ул. Попова (№ 3) (в промежуток с 17:00 до 18:00).

5. На регулируемом пешеходном переходе, предназначенном для пересечения ул. Пушкина через трамвайные пути (№ 4), рекомендуется создать внеуличный пешеходный переход.

\section{Список литературы}

1. Лептюхова О.Ю. Комплексная оценка потребительского качества пешеходных коммуникаций в городских районах: дис. ... канд. техн. наук / Моск. гос. строит. ун-т. - М., 2014. - 191 с.

2. Автомобилизация в России продолжила рост [Электронный pecypc]. - URL: http://mclarenf-1.com/news-115780-avtomobilizaciya-vrossii-prodolzghila-rost.html (дата обращения: 25.02.2016).

3. Пермский край: сведения о показателях состояния безопасности дорожного движения [Электронный pecypc]. - URL: http://www.gibdd.ru/r/59/stat (дата обращения: 25.02.2016).

4. Якимов М.Р. Анализ влияния различных сценариев развития транспортной системы крупного города на возможные варианты нарушения целостности городской структуры // Вестник транспорта Поволжья. - 2011. - № 1 (25). - С. 18-23.

5. Черевко С.Н. Строительство парковок в стесненных городских условиях [Электронный ресурс] // Инженерный вестник Дона. - 2013. - 
№ 3 (26). - URL: http://ivdon.ru/uploads/article/pdf/R_53_Cherevko.pdf_ 1934.pdf (дата обращения: 31.08.2016).

6. Ботиков А.В. Проблемы повышения безопасности дорожного движения // Вестник Воронеж. ин-та МВД России. - 2007. - № 4. С. 99-101.

7. Ким П.А. Повышение безопасности пешеходов на нерегулируемых пешеходных переходах: дис. ... канд. техн. наук / Иркут. гос. техн. ун-т. - Иркутск, 2014. - 149 с.

8. Чикалин Е.Н. Повышение эффективности организации дорожного движения в зонах нерегулируемых пешеходных переходов: дис. ... канд. техн. наук. - Иркутск, 2013. - 210 с.

9. Кузьменко В.Н., Полховская А.С. Повышение безопасности дорожного движения на пешеходном переходе с учетом пешеходного и велосипедного движения // Современные проблемы транспортного комплекса России. - 2013. - № 4. - С. 28-36.

10. Решетова Е.М. Размышления на тему пешеходных переходов в Москве. - М.: Изд-во НИУ ВШЭ, 2012. - 5 с.

11. Семенова О.С, Мордвин А.С. Концепция комплексного освоения подземного пространства на примере территорий в районе станции метро Сокольники в городе Москве // Техника и технологии XXI века: сб. тр. конф., Москва, 29-30 марта 2016 г. - М., 2016. C. 89-95.

12. Доля В.К. Вопросы функционирования пешеходных потоков // Совершенствование организации дорожного движения и перевозок пассажиров и грузов: сб. науч. тр. по результатам ежегод. Междунар. науч.-практ. конф. / под ред. Ф.А. Романюк [и др.]. - Минск: Изд-во Белорус. нац. техн. ун-та, 2014. - С. 238-244.

13. Аникеев Е.А. Управление пешеходными потоками при пиковой интенсивности движения // Программные продукты и системы. 2015. - № 1. - С. 161-166.

14. Пугачев И.Н. Организация движения автомобильного транспорта в городах: учеб. пособие. - Хабаровск: Изд-во Тихоокеан. гос. ун-та, 2005. - $196 \mathrm{c.}$

15. Лобанов Е.М. Транспортная планировка городов: учеб. для студентов вузов. - М.: Транспорт, 1990. - 240 с. 


\section{References}

1. Leptiukhova O.Iu. Kompleksnaia otsenka potrebitel'skogo kachestva peshekhodnykh kommunikatsii $\mathrm{v}$ gorodskikh raionakh [Comprehensive assessment of consumer quality of pedestrian communications in urban areas]. Moscow, 2014. 191 p.

2. Avtomobilizatsiia v Rossii prodolzhila rost [Motorization in Russia continued to grow], available at: http://mclarenf-1.com/news-115780avtomobilizaciya-v-rossii-prodolzghila-rost.html (accessed 25 February 2016).

3. Permskii krai: svedeniia o pokazateliakh sostoianiia bezopasnosti dorozhnogo dvizheniia [Perm territory: information on the indicators of road safety], available at: http://www.gibdd.ru/r/59/stat (accessed 25 Februrary 2016).

4. Iakimov M.R. Analiz vliianiia razlichnykh stsenariev razvitiia transportnoi sistemy krupnogo goroda na vozmozhnye varianty narusheniia tselostnosti gorodskoi struktury [Analysis of the impact of different development scenarios of the large city transport system to the possible options of violations of urban structure integrity]. Vestnik transporta Povolzh'ia, 2011, no. 1 (25), pp. 18-23.

5. Cherevko S.N. Stroitel'stvo parkovok v stesnennykh gorodskikh usloviiakh [Construction of parking in crowded urban environments]. Inzhenernyi vestnik Dona, 2013, no. 3 (26), available at: http://ivdon.ru/uploads/ article/pdf/R_53_Cherevko.pdf_1934.pdf (accessed 31 August 2016).

6. Botikov A.V. Problemy povysheniia bezopasnosti dorozhnogo dvizheniia [Problems of improving road safety]. Vestnik Voronezhskogo instituta Ministerstva vnutrennikh del Rossii, 2007, no. 4, pp. 99-101.

7. Kim P.A. Povyshenie bezopasnosti peshekhodov na nereguliruemykh peshekhodnykh perekhodakh [Improving pedestrian safety on unregulated pedestrian crossings]. Irkutsk, 2014. 149 p.

8. Chikalin E.N. Povyshenie effektivnosti organizatsii dorozhnogo dvizheniia v zonakh nereguliruemykh peshekhodnykh perekhodov [Improving the efficiency of traffic management in the areas of non-regulated pedestrian crossings]. Irkutsk, 2013. 210 p.

9. Kuz'menko V.N., Polkhovskaia A.S. Povyshenie bezopasnosti dorozhnogo dvizheniia na peshekhodnom perekhode s uchetom peshekhodnogo i velosipednogo dvizheniia [Improvement of traffic safety at a pedestrian crossing in view of walking and cycling]. Sovremennye problemy transportnogo kompleksa Rossii, 2013, no. 4, pp. 28-36. 
10. Reshetova E.M. Razmyshleniia na temu peshekhodnykh perekhodov v Moskve [Reflections on pedestrian crossings in Moscow]. Moscow, 2012. 5 p.

11. Semenova O.S, Mordvin A.S. Kontseptsiia kompleksnogo osvoeniia podzemnogo prostranstva na primere territorii $\mathrm{v}$ raione stantsii metro Sokol'niki v gorode Moskve [Conception of complex development of underground space on the example at the territories near the metro station Sokolniki in Moscow]. Sbornik trudov konferentsii "Tekhnika i tekhnologii XXI veka”, Moskva, 29-30 Marta 2016 goda. Moscow, 2016, pp. 89-95.

12. Dolia V.K. Voprosy funktsionirovaniia peshekhodnykh potokov [Issues of pedestrian traffic flows functioning]. Sbornik nauchnykh trudov po rezul'tatam ezhegodnoi Mezhdunarodnoi nauchno-prakticheskoi konferentsii "Sovershenstvovanie organizatsii dorozhnogo dvizheniia i perevozok passazhirov i gruzov". Minsk: Belorusskii natsional'nyi tekhnicheskii universitet, 2014, pp. 238-244.

13. Anikeev E.A. Upravlenie peshekhodnymi potokami pri pikovoi intensivnosti dvizheniia [Pedestrian traffic flow management at peak traffic intensity]. Programmnye produkty i sistemy, 2015, no. 1, pp. 161-166.

14. Pugachev I.N. Organizatsiia dvizheniia avtomobil'nogo transporta $\mathrm{v}$ gorodakh [Organization of automobile traffic in cities]. Khabarovsk: Tikhookeanskii gosudarstvennyi universitet, 2005. 196 p.

15. Lobanov E.M. Transportnaia planirovka gorodov [Transport urban planning: The textbook for university students]. Moscow: Transport, 1990. $240 \mathrm{p}$.

Получено 30.08.2016

\section{Об авторах}

Остерман Екатерина Дмитриевна (Пермь, Россия) - магистрант кафедры «Строительное производство и геотехника», Пермский национальный исследовательский политехнический университет (614990, г. Пермь, Комсомольский пр., 29, e-mail: osterman1993@ mail.ru).

Шутова Ольга Александровна (Пермь, Россия) - старший преподаватель кафедры «Строительное производство и геотехника», Пермский национальный исследовательский политехнический университет (614990, г. Пермь, Комсомольский пр., 29, e-mail: gshperm@ mail.ru). 


\section{About the authors}

Ekaterina D. Osterman (Perm, Russian Federation) - Master Student, Department of Building Production and Geotechnics, Perm National Research Polytechnic University (29, Komsomolsky av., Perm, 614990, Russian Federation, e-mail: osterman1993@mail.ru).

Ol'ga A. Shutova (Perm, Russian Federation) - Senior Lecturer, Department of Building Production and Geotechnics, Perm National Research Polytechnic University (29, Komsomolsky av., Perm, 614990, Russian Federation, e-mail: gshperm@mail.ru). 